\title{
Occurrence and temporal variations of TMDD in the river Rhine, Germany
}

\author{
Arlen A. Guedez • Stephan Frömmel • Peter Diehl • \\ Wilhelm Püttmann
}

Received: 19 March 2009 / Accepted: 14 April 2009 / Published online: 13 June 2009

(C) The Author(s) 2009. This article is published with open access at Springerlink.com

\begin{abstract}
Background, aim, and scope The chemical substance 2,4,7,9-tetramethyl-5-decyne-4,7-diol (TMDD) is a nonionic surfactant used as an industrial defoaming agent and in various other applications. Its commercial name is Surynol $104^{\circledR}$ and the related ethoxylates are also available as Surfynol ${ }^{\circledR} 420,440,465$ and 485 which are characterized by different grades of ethoxylation of TMDD at both hydroxyl functional groups. TMDD and its ethoxylates offer several advantages in waterborne industrial applications in coatings, inks, adhesives as well as in paper industries. TMDD and its ethoxylates can be expected to reach the aquatic environment due its widespread use and its physico-chemical properties. TMDD has previously been detected in several rivers of Germany with concentrations up to $2.5 \mu \mathrm{g} / \mathrm{L}$. In the United States, TMDD was also detected in drinking water. However, detailed studies
\end{abstract}

Responsible editor: Walter Giger

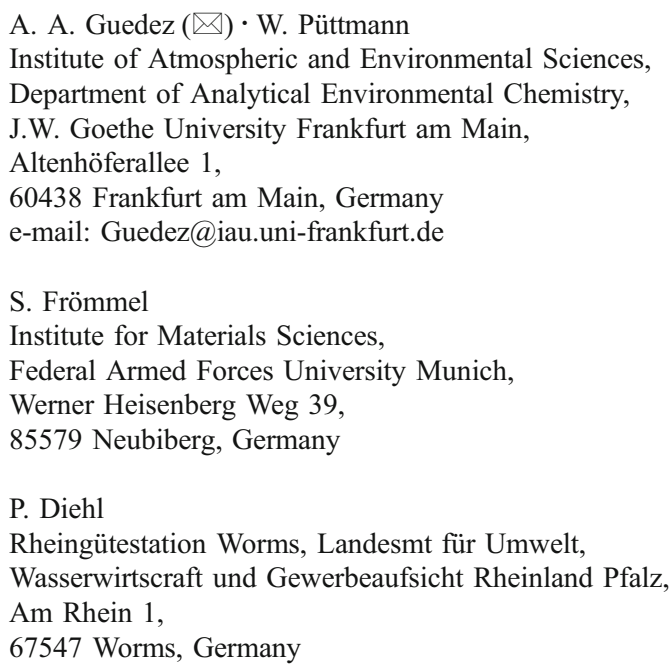

about its presence and distribution in the aquatic environment have not been carried out so far. The aim of the present study was the analysis of the spatial and temporal concentration variations of TMDD in the river Rhine at the Rheingütestation Worms $(443.3 \mathrm{~km})$. Moreover, the transported load in the Rhine was investigated during two entire days and 7 weeks between November 2007 and January 2008.

Materials and methods The sampling was carried out at three different sampling points across the river. Sampling point MWL1 is located in the left part of the river, MWL2 in the middle part, and MWL4 in the right part. One more sampling site (MWL3) was run by the monitoring station until the end of 2006, but was put out of service due to financial constrains. The water at the left side of the river Rhine (MWL1) is influenced by sewage from a big chemical plant in Ludwigshafen and by the sewage water from this city. The water at the right side of the river Rhine (MWL4) is largely composed of the water inflow from river Neckar, discharging into Rhine $14.9 \mathrm{~km}$ upstream from the sampling point and of communal and industrial wastewater from the city Mannheim. The water from the middle of the river (MWL2) is largely composed of water from the upper Rhine. Water samples were collected in 1-L bottles by an automatic sampler. The water samples were concentrated by use of solid-phase extraction (SPE) using Bond Elut PPL cartridges and quantified by use of gas chromatographymass spectrometry (GC-MS). The quantification was carried out with the internal standard method. Based on these results, concentration variations were determined for the day profiles and week profiles. The total number of analyzed samples was 219 .

Results The results of this study provide information on the temporal concentration variability of TMDD in river Rhine in a cross section at one particular sampling point (443.3 km). TMDD was detected in all analyzed water samples at high 
concentrations. The mean concentrations during the 2 days were $314 \mathrm{ng} / \mathrm{L}$ in MWL1, $246 \mathrm{ng} / \mathrm{L}$ in MWL2, and $286 \mathrm{ng} / \mathrm{L}$ in MWL4. The variation of concentrations was low in the day profiles. In the week profiles, a trend of increasing TMDD concentrations was detected particularly in January 2008, when TMDD concentrations reached values up to $1,330 \mathrm{ng} / \mathrm{L}$ in MWL1. The mean TMDD concentrations during the week profiles were $540 \mathrm{ng} / \mathrm{L}$ in MWL1, $484 \mathrm{ng} / \mathrm{L}$ in MWL2, and $576 \mathrm{ng} / \mathrm{L}$ in MWL4. The loads of TMDD were also determined and revealed to be comparable in all three sections of the river. The chemical plant located at the left side of the Rhine is not contributing additional TMDD to the river. The load of TMDD has been determined to be $62.8 \mathrm{~kg} / \mathrm{d}$ on average during the entire period. By extrapolation of data obtained from seven week profiles the annual load was calculated to $23 \mathrm{t} / \mathrm{a}$.

Discussion The permanent high TMDD concentrations during the investigation period indicate an almost constant discharge of TMDD into the river. This observation argues for effluents of municipal wastewater treatment plants as the most likely source of TMDD in the river. Another possible source might be the degradation of ethoxylates of TMDD (Surfynol ${ }^{\circledR}$ series 400), in the WWTPs under formation of TMDD followed by discharge into the river. TMDD has to be considered as a high-production-volume (HPV) chemical based on the high concentrations found in this study. In the United States, TMDD is already in the list of HPV chemicals from the Environmental Protection Agency (EPA). However, the amount of TMDD production in Europe is unknown so far and also the biodegradation rates of TMDD in WWTPs have not been investigated.

Conclusions TMDD was found in high concentrations during the entire sampling period in the Rhine river at the three sampling points. During the sampling period, TMDD concentrations remained constant in each part of the river. These results show that TMDD is uniformly distributed in the water collected at three sampling points located across the river. 'Waves' of exceptionally high concentrations of TMDD could not be detected during the sampling period. These results indicate that the effluents of WWTPs have to be considered as the most important sources of TMDD in river Rhine.

Recommendations and perspectives Based also on the occurrence of TMDD in different surface waters of Germany with concentrations up to $2,500 \mathrm{ng} / \mathrm{L}$ and its presence in drinking water in the USA, more detailed investigations regarding its sources and distribution in the aquatic environment are required. Moreover, the knowledge with respect to its ecotoxicity and its biodegradation pathway is scarce and has to be gained in more detail. Further research is necessary to investigate the rate of elimination of TMDD in municipal and industrial wastewater treatment plants in order to clarify the degradation rate of TMDD and to determine to which extent effluents of WWTPs contribute to the input of TMDD into surface waters. Supplementary studies are needed to clarify whether the ethoxylates of TMDD (known as Surfynol $400^{\circledR}$ series) are hydrolyzed in the aquatic environment resulting in formation of TMDD similar to the well known cleavage of nonylphenol ethoxylates into nonylphenols. The stability of TMDD under anaerobic conditions in groundwater is also unknown and should be studied.

Keywords 2,4,7,9-tetramethyl-5-decyne-4,7-diol . River Rhine · Solid-phase extraction · Surfactants · TMDD · Quantification . TMDD spatial and temporal concentration variations

\section{Background, aim, and scope}

2,4,7,9-Tetramethyl-5-decyne-4,7-diol (TMDD) and the related ethoxylates are non-ionic acetylenic diol surfactants belonging to the group of so called gemini surfactants (Air Products and Chemicals, Inc 2003). Conventional (monomeric) surfactants have a single hydrophobic group connected to a hydrophilic head. In contrast, gemini (dimeric) surfactants have two hydrophilic heads connected by a molecular segment (spacer) to two hydrophobic tails. Acetylenic diol surfactants provide higher efficiency and multi-functionality and are therefore widely used in coatings and many other applications as additives that enable the use of water as a solvent (Galgoci et al. 2004). Their critical micelle concentration $(\mathrm{cmc})$ is lower than that of conventional monomeric surfactants making them more attractive in applications, where a lower concentration of surfactant is required. Thereby, their tendency to stabilize foam is very low, making them suitable for several uses such as in printing inks (Krishnan et al. 1999; Loria and Tai 1995). TMDD as such is available on the market as Surfynol ${ }^{\circledR} 104$ (Air Products and Chemicals, Inc 2003). TMDD has various benefits in coatings, wood finishes, varnishes, cements, and in metalworking fluids (Air Products and Chemicals, Inc 2001). The related ethoxylates are present as several products Surfynol ${ }^{\circledR} 420,440,465$ and 485 (Fig. 1). The Surfynol ${ }^{\circledR}$ 400 series represents ethoxylated acetylenic-based surfactants. The ethoxylation enables the production of surfactants, which exhibit a variation in properties such as surface tension, cloud point and water solubility (Galgoci et al. 2004). Increase of the ethylene oxide content increases the water solubility and the hydrophilic-lipophilic balance. Surfynol ${ }^{\circledR} 420$ and 440 have a higher water resistance and they are described as defoaming wetting agents (Air Products and Chemicals, Inc 2004). They are used as effective deairentraining agents in both concrete and oil well cementing. Surfynol ${ }^{\circledR} 465$ and 485 have a higher solubility in water, 


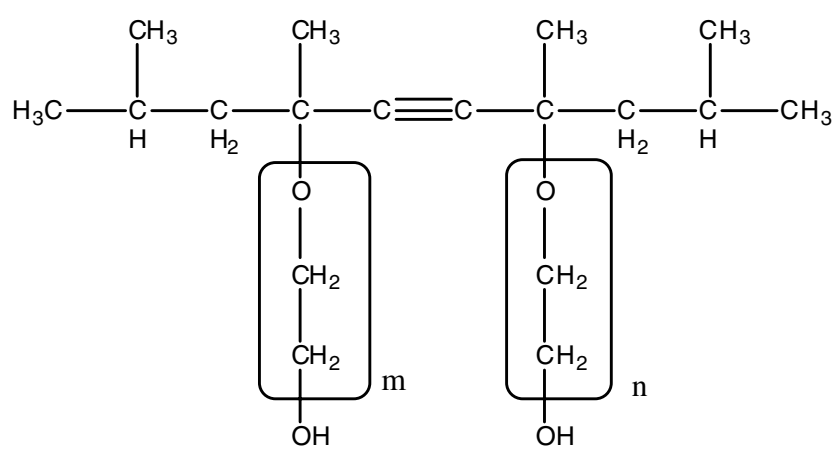

Commercial Name

Ethylene Oxide Content (Moles) $(\mathbf{n}+\mathbf{m})$

\begin{tabular}{cc}
\hline Surfynol 104® & 0 \\
\hline Surfynol $420 \AA$ & 1.3 \\
\hline Surfynol $440 \AA$ & 3.5 \\
\hline Surfynol $465 \AA$ & 10 \\
\hline Surfynol $485 \AA$ & 30 \\
\hline
\end{tabular}

Fig. 1 Ethoxylates of 2,4,7,9-tetramethyl-5-decyne-4,7-diol $(n+m)=$ number of ethoxy groups

slight emulsification properties, low-foaming characteristics, and they are stable in acidic environments, making them suitable to be used in electroplating and acid pickling. Surfynol ${ }^{\circledR} 465$ has a high cloud point for its utilization in high-temperature processes. The Surfynol ${ }^{\circledR} 400$ series surfactants can be used also in waterborne industrial coatings, printing inks, fountain solutions, pressure-sensitive adhesives, paper coatings, synthesis, etc. (Dado 1998; Air Products and Chemicals, Inc 2004). These agents are known since several decades and their surfactant properties have been intensively studied (Leeds et al. 1965; Thelen 1988; Ferri and Stebe 1999).

Most of the applications of TMDD are in open systems with water contact implying that it can easily reach the aquatic environment. Due to its physico-chemical properties, TMDD is expected to remain largely in the water phase since the solubility in water is high $(1.7 \mathrm{~g} / \mathrm{L})$ and the Henry's Law constant is low $\left(8.58 \times 10^{-7}\right.$ atm. $\mathrm{m}^{3} / \mathrm{mol}$; Air Products and Chemicals, Inc 2002). According to the safety data sheet $(91 / 150 / \mathrm{EWG})$, TMDD is expected to pose a low risk for water with respect to aquatic organisms. Studies about its toxicity to aquatic invertebrates and to aquatic plants were made by Air Products and Chemicals in 2002. The determined 48-h $\mathrm{EC}_{50}$ value was $91 \mathrm{mg} / \mathrm{L}$ for Daphia magna and $15 \mathrm{mg} / \mathrm{L}$ for Selenastrum capricornutum (Algae) for cell growth inhibition (72 h).

Reports on the presence of TMDD in the aquatic environment are scarce until now. TMDD has been detected as water contaminant for the first time in water samples filled in beverage carton packages at concentrations up to $69 \mu \mathrm{g} / \mathrm{L}$ (Kleinschnitz and Schreier 1998). Dsikowitzky et al. (2004a, b) reported the occurrence of TMDD in water samples from the Lippe river, Germany in all (19) sampling locations at concentrations ranging between 10 and $1,500 \mathrm{ng} / \mathrm{L}$. The loads of TMDD in Lippe river were also calculated and varied significantly reaching the highest value of $1,330 \mathrm{~g} / \mathrm{d}$. Data from the LANUV (Landesamt für Natur Umwelt und Verbraucherschutz) of North-Rhine-Westphalia (state in Germany) also indicate the presence of TMDD in different rivers of Western Germany. During the year 2007, TMDD was found in the rivers Wupper and Ruhr at concentrations reaching values up to $2.50 \mu \mathrm{g} / \mathrm{L}$ (LANUV, 2007 at http:// luadb.lds.nrw.de/LUA/gues/welcome.htm). TMDD was also detected with a concentration of $190 \mathrm{ng} / \mathrm{L}$ in water samples from the river Meuse in the Netherlands (Hankemeier et al. 1999) and with concentrations between 720 and 2,300 ng/L at eight sampling points along the river Rhine (Schwarzbauer and Heim 2005). A clear trend of the TMDD concentration variations along the river could not be established in this study. More recently, TMDD was identified in finished drinking water with concentrations up to $0.24 \mu \mathrm{g} / \mathrm{L}$ in the USA (Loraine and Pettigrove 2006) and in the Colorado River (Snyder et al. 2001). Until now, detailed studies about the occurrence and distribution of TMDD in the environment are scarce although TMDD is currently used for abundant applications in industry. Likewise, it is unclear how TMDD is introduced into the rivers but wastewater treatment plants discharging their effluents continuously into the rivers might be the prominent source.

This paper contains the results of the quantification of TMDD in the river Rhine of Germany in the time span from November 2007 to January 2008. TMDD concentrations were determined during two entire days and 7 weeks, in order to recognize temporal concentration variations. Loads were also determined to calculate the transported amount of TMDD in a transversal section of the river.

\section{Materials and methods}

\subsection{Sampling}

Sampling was carried out in the river Rhine between November 2007 and January 2008 in two occasions, from 19/11/07 until 16/12/07 and from 07/01/08 until 27/01/08. Parameters including water temperature, runoff, turbidity, and water level were recorded on each sampling occasion. The water samples were collected by the Rheingütestation Worms, which is a monitoring station located at kilometer 443.3 of the Rhine. This station is equipped with three sampling systems (MWL1, MWL2, and MWL4) located across the river. MWL1 is located on the left side, MWL2 in the middle and MWL4 on the right side of the river Rhine. Each sampling system is equipped with three autosamplers SP II-A (MAXX Mess- und Probennahmetechnik 
$\mathrm{GmbH}$, Germany) for routine, incident and alarm monitoring. The water samples were pumped from a $50-\mathrm{cm}$ depth with submersible pumps, which are capable of pumping $10 \mathrm{~m}^{3}$ of water from the Rhine per hour and can be programmed to collect a defined quantity of water at regular rates. This procedure enables the collection of composite samples. Each autosampler is connected with 12 water collectors, which are kept at $4^{\circ} \mathrm{C}$. The 24 -h composite samples were collected by taking $15 \mathrm{~mL}$ of water every 10 min during the entire day.

The three sampling points across the river represent three sections of the river, which can be distinguished with respect to different influences on the water composition. The water at the left side of the river Rhine (MWL1) is influenced by sewage from a big chemical plant in Ludwigshafen and by the sewage water from this city. The water at the right side of the river Rhine (MWL4) is largely composed of the water inflow from river Neckar, discharging into Rhine $14.9 \mathrm{~km}$ upstream from the sampling point and of wastewater from the city of Mannheim. The water in the middle of the river (MWL2) is largely composed of water from the upper Rhine.

Water samples were collected in 1-L brown glass bottles and stored under cooling at $4{ }^{\circ} \mathrm{C}$ in the dark till processing in the laboratory. The bottles were pre-cleaned by washing and flushing several times with distilled water and finally with methanol purified by distillation. The bottles were dried by heating to $125^{\circ} \mathrm{C}$.

At the beginning of the sampling campaign, water samples were also taken directly from Rhine (bridge) in order to find out whether the water supply line or the conduit system of the station could have an influence on the TMMD concentrations found in the water samples collected by the automatic sampling system. The measured concentrations in water samples taken directly from the stream and in water samples collected at the same time by the automatic sampling system were similar indicating that the conduit system and the water supply line of the station do not modify the results.

The TMDD loads at different sections of the transversal profile were calculated using the measured concentration and water flow from the period of sampling. For the calculation of the total load, the cross section of the river has been divided into three sub-sections. In the sub-section representing the middle of the river, the volume of water flow is expected to be three times higher than in both subsections from the left and right side of the river. This estimation is confirmed by monthly calculations with analytical data made by the Rheingütestation.

\subsubsection{Day and week profiles}

In order to study the variation of the TMDD concentrations in the river during a day, 2-h composite water samples were collected from each sampling point on 17/10/07 and 07/11/07. For this purpose, $35 \mathrm{~mL}$ of water were collected every $2 \mathrm{~min}$, leading to an overall sample amount of 36 samples per day for the three sampling points.

For the week profiles, 24-h composite samples were taken from each sampling point by mixing every $10 \mathrm{~min}$ $15 \mathrm{~mL}$ of water during the day. Sampling bottles were changed each day at $12 \mathrm{am}$. In total, 21 water samples were obtained per week since each day one 24-h composite water sample was collected per sampling point. The total number of samples from the week profile was 147 for the whole period.

\subsection{Sample preparation and analysis}

The water samples $(1 \mathrm{~L})$ were filtered through pre-extracted (dichloromethane) paper filters $(5971 / 2$, Schleicher \& Schuell) in order to remove coarse particles and suspended solids. These filters provided a low blank value for TMDD and a rapid filtration at the same time. For the extraction of the target compounds, solid-phase extraction (SPE) was carried out by use of Bond Elute PPL cartridges (Varian, $1 \mathrm{~mL}$; Fries and Püttmann 2001). Prior to use, the cartridges were rinsed with $1 \mathrm{~mL}$ methanol and then conditioned with $1 \mathrm{~mL}$ methanol/acetonitrile (50:50) and distilled water. The water samples were drawn through the cartridges at low pressure (approximately $800 \mathrm{mbar}$ ). Then, the cartridges were dried with high-purity nitrogen and finally eluted with $1 \mathrm{~mL}$ methanol/acetonitrile. After extraction, the samples were analyzed by gas chromatography coupled to mass spectrometry (GC-MS). The gas chromatograph was a Fisons GC 800, equipped with a BP-X5 capillary column (30 m length, $0.25 \mathrm{~mm}$ inner diameter, and $0.25 \mu \mathrm{m}$ film thickness). The oven temperature started at $80^{\circ} \mathrm{C}$ and was raised to $300^{\circ} \mathrm{C}$ at the rate of $4^{\circ} \mathrm{C} / \mathrm{min}$. The mass spectrometer (Fisons MD 800) was operated using electron ionization (EI, $70 \mathrm{eV}$ ) in full-scan mode. The extracts, containing added squalane $(2 \mu \mathrm{g})$ as internal standard were injected in splitless mode. Helium was used as carrier gas.

The identification of the analyte was made by a GC-MS spectrum library (Wiley Register of Mass Spectral Data, 8th electronic version) and verified by comparing the mass spectra and the retention time with the TMDD standard obtained from Sigma-Aldrich. Figure 2 shows the mass spectrum of TMDD recorded by GC-MS analysis of reference material. The quantitation was carried out in the full-scan mode using the characteristic fragment ion $\mathrm{m} / \mathrm{z}$ 109 in order to avoid errors due to peak overlapping. Therefore, the correction and response factors $K$ and $R$ had to be calculated. The correction factor is the peak area of TMDD in the total ion chromatogram (TIC) divided by the peak area of TMDD in the equivalent mass trace used for quantitation $(\mathrm{m} / \mathrm{z}$ 109). The response factor was measured 
Fig. $2 \mathrm{EI}^{+}$mass spectrum of TMDD obtained by GC-MS analysis of reference material. The fragment $m / z=109$ is used for quantitation of the compound

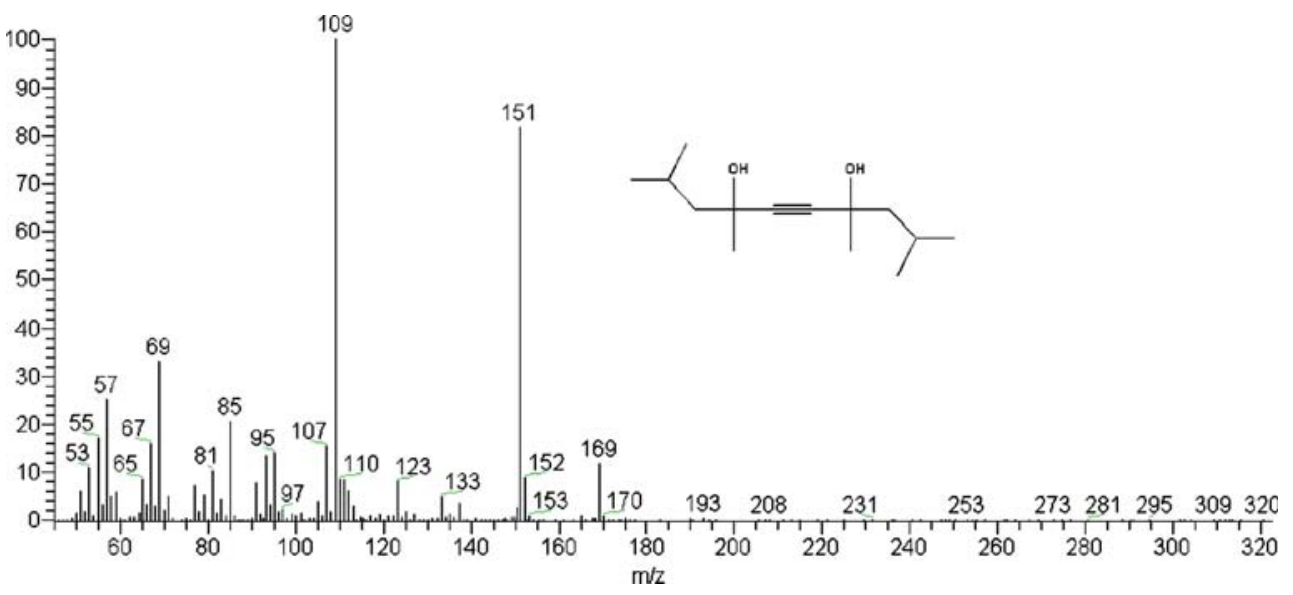

from an analyzed standard solution spiked with $2 \mu \mathrm{g}$ of TMDD and $2 \mu \mathrm{g}$ squalane. The response factor was determined by dividing the peak area for TMDD by the peak area of squalane in the TIC. These factors were determined before each series of measurements. The internal standard method was selected instead of the external standard method for calibration, because TMDD was not the only substance that was quantified during this study.

The blank was determined to be $5 \mathrm{ng} / \mathrm{L}$. The limit of quantitation was calculated in accordance with DIN 32645 (1994) and provided a value of $26 \mathrm{ng} / \mathrm{L}$. For the calculation of the recovery rate water samples were spiked with prepared standard solutions of TMDD (100 ng/L). All spiked samples were extracted by SPE and analyzed with GC-MS. The recovery rate was $96 \%$. The relative standard deviation for TMDD at this concentration was $6 \%$.

\section{Results}

\subsection{Day profiles}

TMDD was found in all analyzed samples $(n=72)$. Table 1 shows the measured analyte concentrations for the 2-day profiles $17 / 10 / 07$ and $07 / 11 / 07$. The concentrations were calculated based on 2-h composite samples per sampling point for the 2 days resulting in 72 samples overall. During these two days, TMDD could be found in mean concentrations higher than $200 \mathrm{ng} / \mathrm{L}$ in all of the three sampling points MWL1, MWL2, MWL4 (see Table 1). The mean concentration of TMDD in water samples from both days $(n=72)$ was $268 \mathrm{ng} / \mathrm{L}$. The concentrations provided no remarkable variation during a day (Fig. 3). The highest mean TMDD concentration during the 2 days $(314 \mathrm{ng} / \mathrm{L})$ was detected in the left section of the river (MWL1) which is influenced by a sewage treatment plant of a chemical plant discharging approximately $4,500 \mathrm{~L} / \mathrm{s}$ into the Rhine. In the middle section (MWL2), which is largely composed of water from the Upper Rhine, the lowest mean TMDD concentration $(246 \mathrm{ng} / \mathrm{L})$ was measured. At the right section (MWL4), which is largely composed by water from the river Neckar, a mean TMDD concentration of $286 \mathrm{ng} / \mathrm{L}$ was determined. The load of TMDD was calculated for each sampling point, too. For both the left (MWL1) and the right parts of the river (MWL4), the mean load of TMDD was calculated 4.2 and $3.8 \mathrm{~kg} / \mathrm{d}$ respectively. For the middle part of the river (MWL2), the calculated load was the highest (see Table 1; Fig. 4). Despite similar TMDD concentrations in all three river segments, the load in the middle of the

Table 1 Concentrations and loads of TMDD during the day profiles at the monitoring station Worms in river Rhine

\begin{tabular}{|c|c|c|c|c|c|c|}
\hline & \multicolumn{2}{|l|}{ MWL1 } & \multicolumn{2}{|l|}{ MWL2 } & \multicolumn{2}{|l|}{ MWL4 } \\
\hline & Concentration $(\mathrm{ng} / \mathrm{L})$ & Load $(\mathrm{kg} / \mathrm{d})$ & Concentration (ng/L) & Load $(\mathrm{kg} / \mathrm{d})$ & Concentration $(\mathrm{ng} / \mathrm{L})$ & Load $(\mathrm{kg} / \mathrm{d})$ \\
\hline Min & 217 & 2.5 & 185 & 7.6 & 222 & 3.1 \\
\hline Median & 309 & 4.2 & 241 & 9.3 & 287 & 3.7 \\
\hline Mean & 314 & 4.2 & 246 & 9.8 & 286 & 3.8 \\
\hline Max & 451 & 6.9 & 342 & 15.3 & 334 & 4.4 \\
\hline SD & 50 & 1.2 & 35 & 2.0 & 24 & 0.44 \\
\hline
\end{tabular}

$S D$ standard deviation 
Fig. 3 Concentrations of TMDD in river Rhine during the day profiles

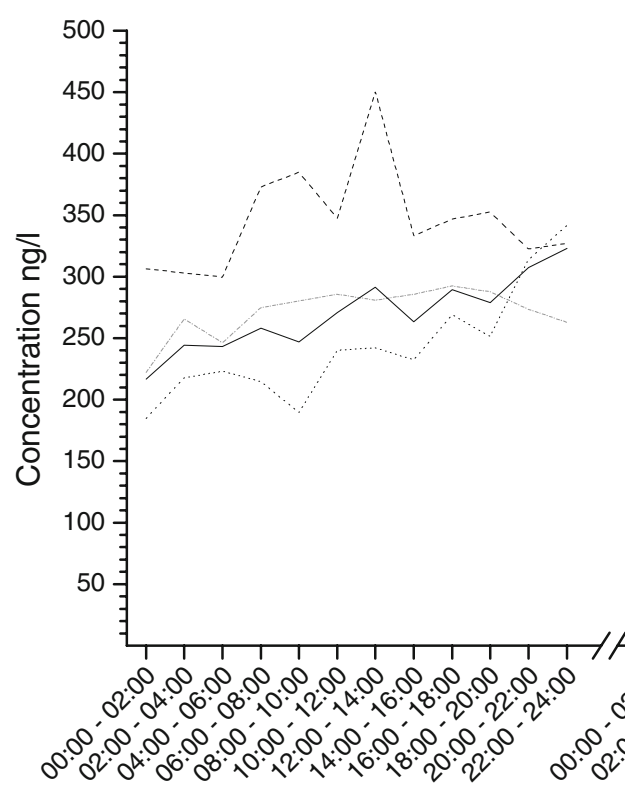

17.10.2007
-... Concentration MWL1

Concentration MWL2

Concentration MWL4

- Mean concentration

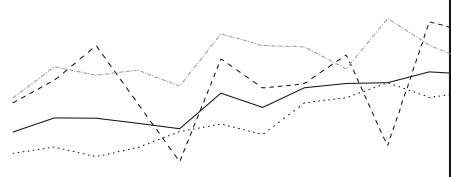

river is the highest because the volume of water, which flows through this section is three times higher than in the right and left sections.

\subsection{Week profiles}

\subsubsection{TMDD concentrations}

Results from the measurement of TMDD concentrations for 7 weeks (two sampling campaigns) in each part of the river are represented in Fig. 5. TMDD is present at all three

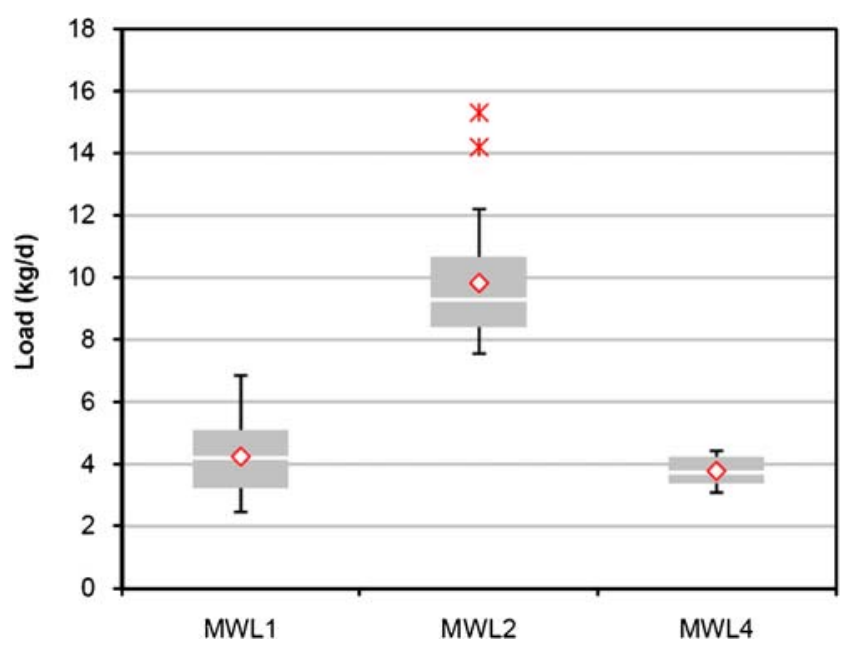

Fig. 4 Loads of TMDD in each sampling point in the river Rhine during the day profiles. The bottom of each box is the 25th percentile, the top is the 75th percentile and the point in the middle is the mean TMDD concentration. The vertical lines represent the whiskers. Outside values are marked by asterisks sampling points at largely similar concentrations, which vary almost parallel with the time. During the first sampling campaign in November and December 2007, concentration variations were moderate but during the second sampling campaign in January 2008, a significant increase of TMDD concentrations from approximately 500 to $1,000 \mathrm{ng} / \mathrm{L}$ at about mid-January was detected (see Fig. 5). However, this increase was not depending on water level changes. Table 2 summarizes the mean TMDD concentrations obtained from the week profiles. The highest concentration was found in the left part of the river with $1,330 \mathrm{ng} / \mathrm{L}$. However, the mean concentrations determined from each sampling point were similar with values around $500 \mathrm{ng} / \mathrm{L}$. The total average TMDD concentration for the entire period was $514 \mathrm{ng} / \mathrm{L}$ taking the three sampling points into account. High TMDD concentrations were also found by Schwarzbauer and Heim (2005) during spot sampling downstream at the Rhine with concentrations ranging between 720 and 2,300 $\mathrm{ng} / \mathrm{L}$. In the annual report of the monitoring station Weil (Amt für Umwelt und Energie Basel-Stadt 2001) the presence of TMDD in the Rhine was reported too. During this year, the TMDD concentration exceeded the value of $0.23 \mu \mathrm{g} / \mathrm{L}$ in 20 days. For comparison, concentrations of other compounds previously quantified in the Rhine are mentioned. Jonkers et al. (2003) found nonylphenols in the Rhine estuary with concentrations between 31-147 ng/L. Skutlarek et al. (2006) analyzed perfluorinated surfactants in the Rhine and the major component was perfluorobutane sulfonate (PFBS) with a concentration up to $46 \mathrm{ng} / \mathrm{L}$. Compared to the concentrations of previously detected nonylphenols and perfluorinated surfactants, the concentrations of TMDD obtained in the present study were considerably 
Fig. 5 TMDD concentrations in river Rhine during the week profiles

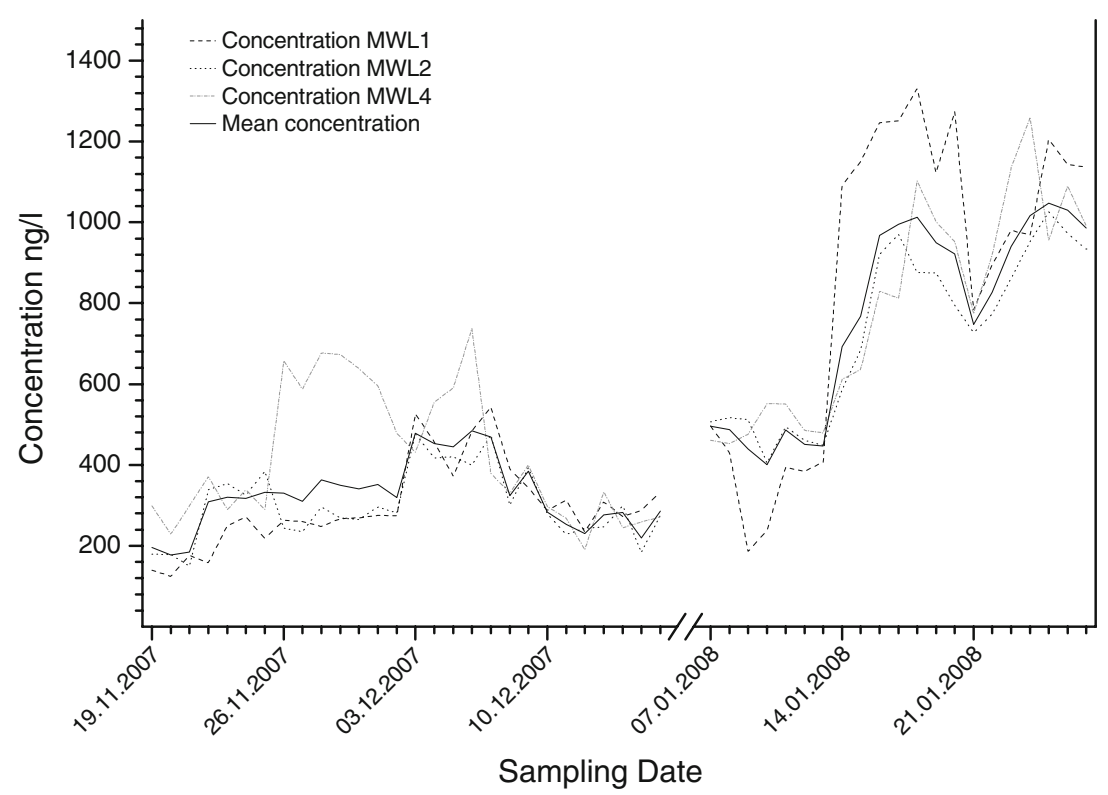

higher implicating that TMDD is currently one of the most abundant organic contaminants in the river Rhine.

\subsubsection{TMDD loads}

Loads of TMDD in river Rhine were also determined using the data from the week profiles. Data are presented in Table 2 and indicate a largely homogeneous load across the Rhine profile. In the middle of the river, the load is approximately three times higher than at both sides due to the fact, that the middle section of the river transports a three times higher water volume than both side sections. From these data, a total mean load of $62.8 \mathrm{~kg} / \mathrm{d}$ or approximately $23 \mathrm{t} / \mathrm{a}$ have been calculated.

In previous studies, loads of other compounds in the river Rhine have been calculated. Sacher et al. (2008) estimated the average annual transport of carbamazepine (1.4-7.0 t/a equivalent to $3.8-19.2 \mathrm{~kg} / \mathrm{d})$ and diclofenac $(0.5-3.3 \mathrm{t} / \mathrm{a}$ equivalent to $1.4-9.0 \mathrm{~kg} / \mathrm{d}$ ) in the river Rhine at Karlsruhe during 1997-2006. The data indicate that the load of TMMD in river Rhine is by far higher than for all other compounds. Substances like the complexing agents benzotriazole and tolyltriazole have been found in the Rhine at Weil (border between Switzerland and Germany) with loads of 22.3 and $7.4 \mathrm{~kg} / \mathrm{d}$ and at Rekingen (Switzerland) with loads of 8.2 and $2.6 \mathrm{~kg} / \mathrm{d}$, respectively (Giger et al. 2006). These mass flows are lower than those determined for TMDD $(62.8 \mathrm{~kg} / \mathrm{d})$ in the present study. However, one compound with higher loads compared to TMDD has been reported, too. Schmidt et al. (2004) reported EDTA loads in river Rhine at Ludwigshafen in the years 1999 (191 t/a equivalent to $523 \mathrm{~kg} / \mathrm{d}), 2000$ (174 t/a equivalent to $477 \mathrm{~kg} / \mathrm{d}$ ) and 2001 (192 t/a equivalent to $526 \mathrm{~kg} / \mathrm{d}$ ) and during these years the sales volumes for EDTA were estimated at roughly 4,000 t/a in Germany. These results are confirmed by the data published by the International Commission for the Protection of the Rhine (ICPR, http://had.bafg.de:8080/iksr-zt/) and the German Rhine Commission (www.dk-rhein.de).

Table 2 Concentrations and loads of TMDD during the week profiles at the monitoring station Worms in river Rhine

\begin{tabular}{|c|c|c|c|c|c|c|}
\hline & \multicolumn{2}{|l|}{ MWL1 } & \multicolumn{2}{|l|}{ MWL2 } & \multicolumn{2}{|l|}{ MWL4 } \\
\hline & Concentration $(\mathrm{ng} / \mathrm{L})$ & Load (kg/d) & Concentration $(\mathrm{ng} / \mathrm{L})$ & Load $(\mathrm{kg} / \mathrm{d})$ & Concentration $(\mathrm{ng} / \mathrm{L})$ & Load $(\mathrm{kg} / \mathrm{d})$ \\
\hline Min & 125 & 1.9 & 150 & 6.7 & 191 & 3.4 \\
\hline Median & 372 & 11.3 & 405 & 33.6 & 551 & 13.4 \\
\hline Mean & 540 & 13.2 & 484 & 35.7 & 576 & 14.0 \\
\hline Max & 1330 & 29.6 & 1026 & 74.7 & 1260 & 32.3 \\
\hline SD & 386 & 8.5 & 261 & 17.8 & 279 & 6.3 \\
\hline
\end{tabular}




\section{Discussion}

Results from the present study indicate that TMDD is continuously discharged into the river Rhine at similar concentrations across the whole section of the river. Moreover, the concentrations do not change significantly over the day and even over several weeks in November and December 2007. These observations argue for effluents from wastewater treatment plants (WWTPs) as a major source of TMDD in the river water, since WWTPs are continuously discharging water into the rivers. However, during the three weeks of sampling in January 2008 the variation of TMDD concentrations was higher than during the sampling before and a tendency of increasing concentrations could be observed during January 2008. A conclusive explanation for the variation of TMDD concentrations cannot be given, since a correlation with water level fluctuations is not evident. TMDD has previously been detected in wastewater influents with a mean concentration of $0.73 \mu \mathrm{g} / \mathrm{L}$ (Loraine and Pettigrove 2006) in the United States, but data on TMDD in influents or effluents from WWTPs in Germany are not available until now.

Another possible source of TMDD in the river water might be related to the wide use of various TMDD ethoxylates, which are known as Surfynol ${ }^{\circledR}$ 420, 440, 465, and 485 (see Fig. 1). It is well known since a long time, that ethoxylates are susceptible to hydrolysis resulting in the formation of the alcohols from which they were synthesized. The most prominent example for this hydrolysis is the formation of 4-nonylphenols from the related nonylphenol ethoxylates previously used as detergents in high abundance (Giger et al. 1984). Whether or not TMDD ethoxylates are hydrolyzed in the aquatic environment and particularly in sewage treatment plants under formation of TMDD, is so far unknown.

According to a report from Air Products and Chemicals, Inc (2002), TMDD is inherently biodegradable following the OECD 302A protocol, and the results showed a biodegradation rate of $15.7 \%$ during 57 days in domestic activated sludge. This biodegradation rate is relatively low assuming sludge retention times of approximately 10 days in conventional sewage treatment plants. According to the molecular structure of TMDD with one alkyne and two hydroxyl functional groups, TMDD should be expected to be biodegradable to some extent. However, the biodegradability of a substance depends on several parameters, which cannot be easily predicted. Therefore, more studies about its biodegradability should be carried out and should be compared with elimination rates determined at sewage treatment plants.

Based on the high concentrations and loads detected in rivers, TMDD is expected to be produced in high quantities. The TMDD mean load in river Rhine at Worms was $62.8 \mathrm{~kg} / \mathrm{d}$, which is equivalent to approximately $23 \mathrm{t} / \mathrm{a}$.
Based on these data, TMDD is a high-production-volume chemical $(\geq 1,000 \mathrm{t} / \mathrm{a})$ even when biodegradation in sewage treatment plants is less than $90 \%$ as demanded for non-ionic surfactants. However, the annual production of TMDD in Germany or in Europe is unknown. Although TMDD is present in the list of low production volume chemicals of the ESIS (European chemical substances information system), the compound was pre-registered to the European Chemicals Agency (ECHA) which manages the registration, evaluation, and authorization for chemical substances in the European Union. According to the established deadline for the complete registration to the ECHA (30. November 2010), this substance can be classified as a compound, which is imported or produced into the EU at a quantity of more than $1,000 \mathrm{t} / \mathrm{a}$ (high production volume (HPV) chemical).

In the United States, TMDD is already listed in the HPV Challenge Program, which includes substances which are produced or imported in quantities of 1 million pounds or more per year (http://iaspub.epa.gov/oppthpv/quicksearch. chemical). Despite its presence in this program, results from extensive investigations of the behavior of TMDD in the aquatic environment have not been reported.

The Rhine river provides drinking water for approximately 20 million people. Principally, the production takes place along the river through bank filtration, which is an important factor to be considered, when high concentrations of a substance are found in the surface water. Furthermore, it is known that the occurrence of polar pollutants in river water can represent a problem for the quality of ground water and drinking water produced by bank filtration (Achten et al. 2002; Fries and Püttmann 2003). However, studies with respect to the behavior of TMDD during bank filtration have not been carried out. Although TMDD and its polyethoxylated homologues are expected to pose a risk for the water quality according to the safety data sheet of the Federal Environmental Agency of Germany (http:// webrigoletto.uba.de/rigoletto/public/welcome.do), studies investigating the distribution of the compound in the aquatic environment are missing so far.

\section{Conclusions}

TMDD was detected in high concentrations in the Rhine at Rheingütestation Worms during November 2007 till January 2008 and was distributed uniformly in a sampling profile across the river. The chemical plant located upstream on the left side of the river had no significant influence on the concentration of TMDD in the river. The spatial and temporal uniform distribution of TMDD in the river argues for a dominating input through effluents of sewage treatment plants. According to the high concentration found 
(mean value of $514 \mathrm{ng} / \mathrm{L}$ ) TMDD has to be regarded as a HPV chemical in accordance with the OECD classification system. Due to the limited biodegradability of TMDD, the substance is not permitted to be used in washing and cleaning products following the EU detergent regulation No. EC 648/2004. Therefore, other applications such as constituent of printing inks, paints, defoamer, adhesives, coatings, etc. have to be considered as sources for the input of TMDD into the sewage. Temporarily occurring 'waves' of significantly increased concentrations of TMDD in the river Rhine are not detectable which argues for a continuous input into the river most likely by effluents of WWTPs. In case of other compounds, such as MTBE waves with concentration peaks were recognized in river Rhine and argue for a discontinuous input of this compound into the river (Gerke et al. 2003).

\section{Recommendations and perspectives}

Some important questions arise considering the high concentrations and loads of TMDD detected in the river Rhine. The data argue for a major input of TMDD into the river by effluents from sewage treatment plants. However, this assumption has to be confirmed by more detailed studies. Analyses of TMDD in influents and effluents of WWTPs are required in order to find out information on the elimination rates and temporal variations of its concentrations.

Supplementary studies are needed to clarify, whether or not the ethoxylates of TMDD (known as Surfynol $400^{\circledR}$ series) are hydrolyzed in the aquatic environment resulting in TMDD similar to the well known cleavage of nonylphenol ethoxylates into nonylphenols.

The already existing toxicity tests for TMDD and its ethoxylates are not sufficient to exclude possible hazards effects on aquatic organisms. Due to the limited biodegradability of TMDD it would be desirable to have data available describing its chronic toxicity to fish and invertebrates.

Furthermore, photolysis and hydrolysis experiments should be realized in order to investigate whether or not TMDD can undergo biological and/or photochemical transformations in the aquatic environment leading to the formation of transformation products, which might also pose a risk to aquatic organisms. Moreover, it has to be clarified, whether TMDD is eliminated through bank filtration and/or by subsequent treatment of the raw water in the water works.

Acknowledgments Thanks go to Mrs. Kolland and Mr. Schwab from the Rheingütestation in Worms for support with sample collection.

Open Access This article is distributed under the terms of the Creative Commons Attribution Noncommercial License which permits any noncommercial use, distribution, and reproduction in any medium, provided the original author(s) and source are credited.

\section{References}

Achten C, Kolb A, Püttmann W (2002) Occurrence of methyl tertbutyl ether (MTBE) in riverbank filtered water and drinking water produced by riverbank filtration. Environ Sci Technol 36 (17):3662-3670

Air Products and Chemicals, Inc. (2001) Surfynol ${ }^{\circledR} 104$ Surfactant

Air Products and Chemicals, Inc. (2002) IUCLID, Data set. 2,4,7,9Tetramethyl-5-decyne-4,7-diol

Air Products and Chemicals, Inc. (2003) $\operatorname{Surfynol}^{\circledR}$, Dynol ${ }^{\mathrm{TM}}$, and EnviroGem ${ }^{\circledR}$ Additives reference guide

Air Products and Chemicals, Inc. (2004) Surfynol ${ }^{\circledR} 400$ series surfactants Surfynol 420, 440, 465, 485 surfactants

Amt für Umwelt und Energie Basel-Stadt (2001) Rheinüberwachungsstation Weil am Rhein. Jahresbericht 2001

Dado G (1998) Preparation of disperse azo dyestuffs in the presence of alkoxylated acetylenic diols. U.S. Pat.\# 5,852,179

DIN 32645 Deutsches Institut für Normung e.V (1994) Nachweis-, Erfassungs- und Bestimmungsgrenze

Dsikowitzky L, Schwarzbauer J, Littke R (2004a) The anthropogenic contribution of the Lippe river (Germany). Part II: quantification of specific organic contaminants. Chemosphere 57:12891300

Dsikowitzky L, Schwarzbauer J, Kronimus A, Littke R (2004b) The anthropogenic contribution to the organic load of the Lippe river (Germany). Part I: qualitative characterisation of low-molecular weight organic compounds. Chemosphere 57:1275-1288

Ferri JK, Stebe KJ (1999) A structure-property study of the dynamic surface tension of three acetylenic diol surfactants. Colloids Surf., A 156:567-577

Fries E, Püttmann W (2001) Occurrence of organophosphate esters in surface water and ground water in Germany. J Environ Monit 3:621-626

Fries E, Püttmann W (2003) Monitoring of the three organophosphate esters TBP, TCEP and TBEP in river water and ground water (Oder, Germany). J Environ Monit 5:346-352

Galgoci EC, Chan SY, Yacoub K (2004) Innovative molecular defoamer technology. Air Products and Chemicals, Inc.

Gerke T, Brandt P, Willemsen HG (2003) MTBE waves in the lower Rhine. In: Proceedings of First European Conference on MTBE, Dresden. In: Bilitewski B, Werner, P. (eds) Beiträge zu Abfallwirtschaft/Altlasten 31:128-136

Giger W, Brunner PH, Schaffner C (1984) 4-Nonylphenol in sewage sludge: accumulation of toxic metabolites from nonionic surfactants. Science 225:623-625

Giger W, Schaffner C, Kohler H (2006) Benzotriazole and tolyltriazole as aquatic contaminants. 1. Input and occurrence in rivers and lakes. Environ Sci Technol 40:7186-7192

Hankemeier Th, Steketee PC, Vreuls JJ, Brinkman UATh (1999) Atline SPE-GC-MS of micropollutants in water using the prepstation. Fresenius J Anal Chem 364:106-112

Jonkers N, Laane RWPM, De Voogt P (2003) Fate of nonylphenol ethoxylates and their metabolites in two Dutch estuaries: evidence of biodegradation in the field. Environ Sci Technol 37:321-327

Krishnan R, Sprycha R (1999) Interactions of acetylenic diol surfactants with polymers Part 1 . Maleic anhydride co-polymers. Colloids Surf., A 149:355-366

Kleinschnitz M, Schreier P (1998) Identification and semi-quantitative determination of a migration contaminant from beverage carton packages into mineral water by on-line solid phase extraction gas chromatography-mass spectrometry (SPE-GC-MS). Chromatographia 48(7/8):581-583

Leeds MW, Tedeschi RJ, Dumovich SJ, Casey AW (1965) Acetylenic non-ionic surfactants. IEC Prod Res Dev 4(4):236-242 
Loraine GA, Pettigrove ME (2006) Seasonal variations in concentrations of pharmaceuticals and personal care products in drinking water and reclaimed wastewater in southern California. Environ Sci Technol 40(3):687-695

Loria AM, Tai I (1995) High temperature jet printing ink. US Pat.\# $5,443,628$

Sacher F, Ehmann M, Gabriel S, Graf C, Brauch HJ (2008) Pharmaceutical residues in the river Rhine-results of a onedecade monitoring programme. J Environ Monit 10:664-670

Schmidt CK, Fleig M, Sacher F, Brauch HJ (2004) Occurrence of aminopolycarboxylates in the aquatic environmental of Germany. Environ Pollut 131:107-124
Schwarzbauer J, Heim S (2005) Lipophilic organic contaminants in the Rhine river, Germany. Water Res 39:4735-4748

Skutlarek D, Exner M, Färber H (2006) Perfluorinated surfactants in surface and drinking waters. Environ Sci Pollut Res 13(5):299307

Snyder S, Kelly K, Grange A, Sovocool GW, Snyder E, Giesy J (2001) Pharmaceuticals and personal care products in the waters of lake Mead, Nevada. In Pharmaceuticals and personal care products in the environment; scientific and regulatory issues. American Chemical Society, Washington DC 7

Thelen G (1988) Verfahren zur Herstellung von Alkindiolen durch Umsetzung von Ketonen mit Acetylen. EU Patent 88,101,430.2 